\title{
Note
}

[Agr. Biol. Chem., Vol. 33, No. 8, p. 1210 1212, 1969]

\section{A Modified Method for Synthesis of Pyridoxylhistamine}

\author{
By Hidehiko Kumagal, Hideaki Yamada and Hiroshi Fukami* \\ Research Institute for Food Science, \\ * Pesticide Research Institute, Kyoto University, Kyoto, Japan \\ Received February 14, 1969
}

In the course of the investigation in our laboratory on the reaction mechanism of pig kidney histaminase, an enzyme-substrate intermediate has been stabilized by reduction with sodium borohydride. To elucidate the binding site of the substrate to the enzyme, the reduced histaminase-histamine complex was hydrolyzed. The hydrolyzate was applied to electrophoresis and existence of pyridoxylhistamine II was confirmed." The pyridoxylhistamine used as an authentic sample was
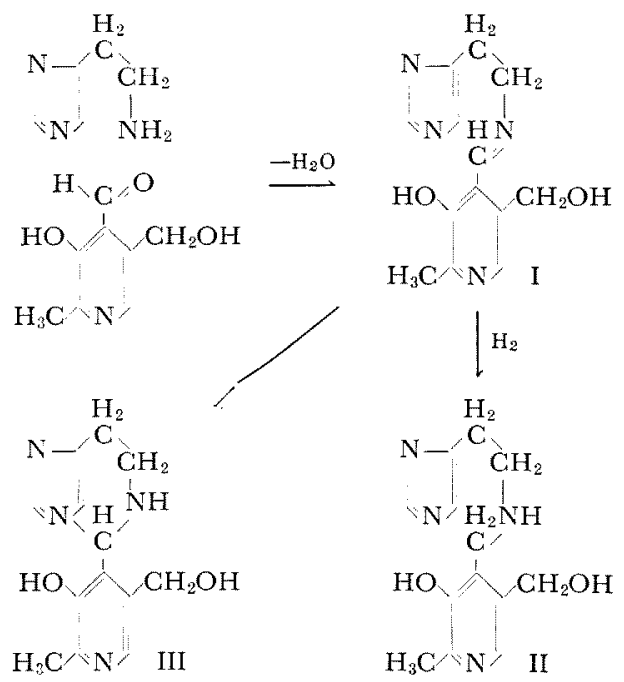

SCHEME 1. synthesized from pyridoxal hydrochloride and histamine according to the method of Heyl et al. ${ }^{2 \prime}$ with modifications.

The modified method for the synthesis of

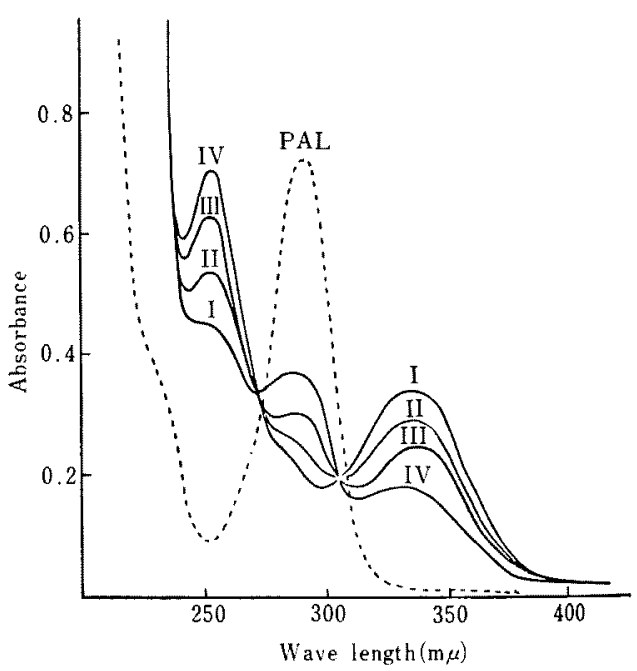

Fig. 1. Absorption Spectra of Pyridoxal in the Presence of Histamine.

The solution consisted of $45 \mu \mathrm{g}$ of pyridoxal hydrochloride and $20 \mu \mathrm{g}$ of histamine in $3.0 \mathrm{ml}$ of ethyl alcohol. Absorption spectra were taken at room temperature with a Beckman DB-G recording spectrophotometer. The spectra were recorded $1 \mathrm{~min}$ (I), $30 \mathrm{~min}$ (II), $60 \mathrm{~min}$ (III) and $12 \mathrm{hr}$ (IV) after addition of histamine. Absorption of pyridoxal alone is indicated as PAL.

2) D. Heyl, E. Luz, A. Harris and K. Folkers, J. Am. Chem. Soc., 70, 3669 (1948).
1) H. Kumagai, T. Nagate, H. Yamada and $H$. Fukami, Biochim. Biophys. Acta, in press. 


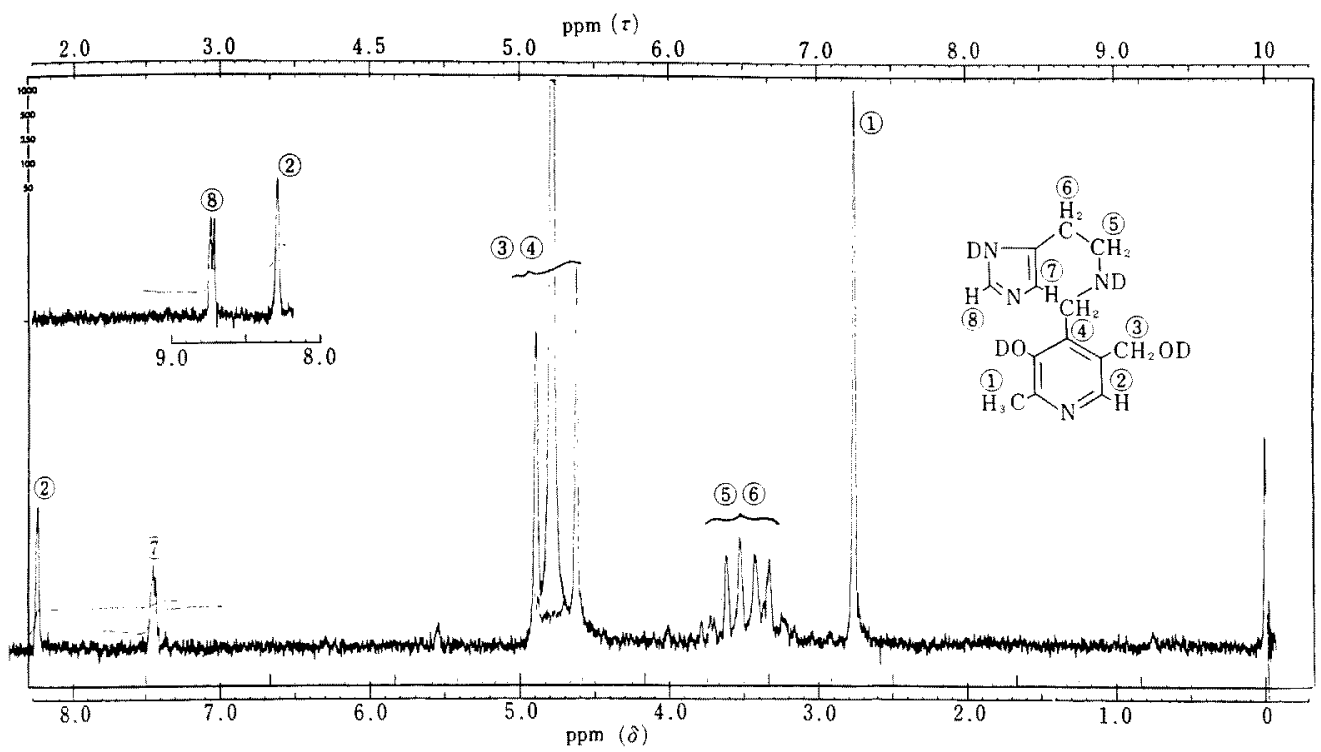

FIG. 2. Nuclear Magnetic Resonance Spectrum of Synthesized Pyridoxylhistamine III.

Twenty-five milligrams of synthesized pyridoxylhistamine was dissolved in $0.6 \mathrm{ml}$ deuterium oxide and the spectrum was taken with a Varian A-60 NMR spectrometer.

pyridoxylhistamine is presented in this paper.

For the purpose of preparing pyridoxylidenehistamine I, pyridoxal was condensed with histamine according to the method of Heyl et al. However, the resultant product did not contain the Schiff base I, but it contained an isomeric compound III exclusively. Preliminary experiments were carried out with the aid of spectroscopic measurements to determine optimum conditions for the preparation of the Schiff base I from pyridoxal and histamine. As shown in Fig. 1, addition of histamine into ethanol solution of pyridoxal hydrochloride resulted in immediate appearance of two absorption bands at 260 and $340 \mathrm{~m} \mu$ due to the formation of the Schiff base I. But these bands disappeared proportionally with time, whereas an increase of a new band at the same wavelength as that of pyridoxal itself was observed. This may mean gradual formation of tetrahydropyridine compound III from the Schiff base I. In fact, pyridoxylhistamine II was obtained in a satisfactory yield when the reduction with sodium borohydride was carried out immediately after addition of pyridoxal hydrochloride into alcoholic solution of histamine.

One gram of histamine dihydrochloride was suspended with $1.0 \mathrm{~g}$ of sodium bicarbonate in $30 \mathrm{ml}$ of ethyl alcohol and the suspension was refluxed for $35 \mathrm{~min}$. To the filtered alcoholic solution, $1.0 \mathrm{~g}$ of pyridoxal hydrochloride was added. After one minute the system was treated with $100 \mathrm{mg}$ of sodium borohydride, and maintained at $30^{\circ} \mathrm{C}$ for one hour. An excess of sodium borohydride was decomposed by addition of $5 \mathrm{ml}$ of $6 \mathrm{~N} \mathrm{HCl}$ solution. The alcoholic- $\mathrm{HCl}$ solution was evaporated to dryness at $50^{\circ} \mathrm{C}$ under reduced pressure, and the obtained brown syrup was dissolved in $5 \mathrm{ml}$ of $0.1 \mathrm{~N} \mathrm{HCl}$ solution and applied to a charcoal column $(1 \times 10 \mathrm{~cm})$ which: had been washed with $0.1 \mathrm{~N} \mathrm{HCl}$. The column was first washed with $0.1 \mathrm{~N} \mathrm{HCl}$, then eluted 
with $\mathrm{H}_{2} \mathrm{O}$. The water eluate was evaporated to dryness and the syrup obtained was dissolved in ethyl alcohol containing a small amount of $\mathrm{H}_{2} \mathrm{O}$. Colorless crystals of pyridoxylhistamine trihydrochloride weighing 600 mg were obtained. Recrystallization was carried out from ethyl alcohol-water. Melting point of the recrystallized material was shown to be $225 \sim 226^{\circ} \mathrm{C}$ (dec.), (literature, ${ }^{2 \prime} \mathrm{mp} 236 \sim$ $237^{\circ} \mathrm{C}$ as the dihydrochloride). Anal. Calcd. for $\mathrm{C}_{13} \mathrm{H}_{21} \mathrm{~N}_{4} \mathrm{O}_{2} \mathrm{Cl}_{3}: \mathrm{C}, 42.10 ; \mathrm{H}, 5.66 ; \mathrm{N}, 15.09$. Found: C, 42.77; H, 5.90; N, 15.25\%.

The NMR spectrum of the recrystallized sample was measured in deuterium oxide. Assignments of all signals are given in Fig. 2.

We wish to thank Prof. K. Ogata and Prof. Y. Morita, Kyoto University, Kyoto, for their interest and advice during this work. 